\title{
Morphology of the lingual papillae in the eastern grey kangaroo
}

\author{
By \\ Shoichi EMURA \\ Heisei College of Health Sciences, Gifu 501-1131, Japan \\ -Received for Publication, May 2, 2016-
}

\begin{abstract}
Key Words: eastern grey kangaroo, lingual papillae, scanning electron microscopy
Summary: We examined the dorsal lingual surface of an adult eastern grey kangaroo (Macropus gigantues) by scanning electron microscopy. The filiform papillae on the lingual apex and anterior body consisted of a main papilla and secondary papillae. The connective tissue core of the filiform papillae on the lingual apex had several processes. The filiform papillae on the lingual posterior body were thread-like in shape. The connective tissue core of the filiform papillae on the lingual posterior body consisted of many slender processes. The fungiform papillae were round in shape. Three vallate papillae with the apex of the triangle directed posteriorly consisted of a groove and pad. Several conical papillae derived from the posterolateral margin of the tongue where foliate papillae have been shown to be distributed in many other animal species. The surface structure of the tongue in the eastern grey kangaroo resembles that of the red kangaroo.
\end{abstract}

Many studies have reported the structures of the lingual surfaces in various animals. In the order Marsupialia, there have been a few scanning electron microscopy (SEM) studies on the tongues of opossum (Krause and Cutts, 1982), koala (Kobayashi et al., 2003), red kangaroo (Emura et al., 2004), sugar glider (Emura, 2011) and brush-tailed rat kangaroo (Emura et al., 2014). Such studies have revealed variations in the morphology and distribution of papillae on the dorsal lingual surface among animal species.

However, no SEM study on the tongue of the eastern grey kangaroo has been carried out. In this study, the dorsal lingual surface of the eastern grey kangaroo was examined three-dimensionally, in order to compare the results with those of previous reports on other animals.

\section{Materials and Methods}

The tongue of an adult eastern grey kangaroo (Macropus gigantues) of the family Macropodidae was used in this study. The tongue was fixed in $10 \%$ formalin. Small blocks containing papillae were cut with a razor blade, and post-fixed with $1 \%$ osmium tetroxide for 1 h. Thereafter, the specimens were dehydrated through a graded series of acetone and critical-point-dried. To show the three-dimensional connective tissue structure of the lamina propria of the mucosa, some of the samples were washed in distilled water after fixation and macerated in $3.5 \mathrm{~N} \mathrm{HCl}$ at $35{ }^{\circ} \mathrm{C}$ for three days. After maceration, the tissues were washed in distilled water, post-fixed in $1 \%$ osmium tetroxide for $1 \mathrm{~h}$, and dehydrated in a series of acetone and critical-point-dried. All specimens were sputtered with Pt-Pd before being examined by SEM (Hitachi S-3500N, Tokyo, Japan) at an accelerating voltage of 10 $\mathrm{kV}$.

\section{Results}

\section{General observations}

Macroscopically, the tongue of the brush-tailed rat kangaroo was about $15 \mathrm{~cm}$ long. At the posterior end of the lingual body, a triangular arrangement of three vallate papillae, with the apex of the triangle directed posteriorly, was observed (Fig. 1).

\section{Scanning electron microscopy}

The filiform papillae on the lingual apex and anterior body consisted of a main papilla and secondary papillae (Fig. 2a, 3). The connective tissue core of the filiform papillae on the lingual apex had several processes (Fig. 


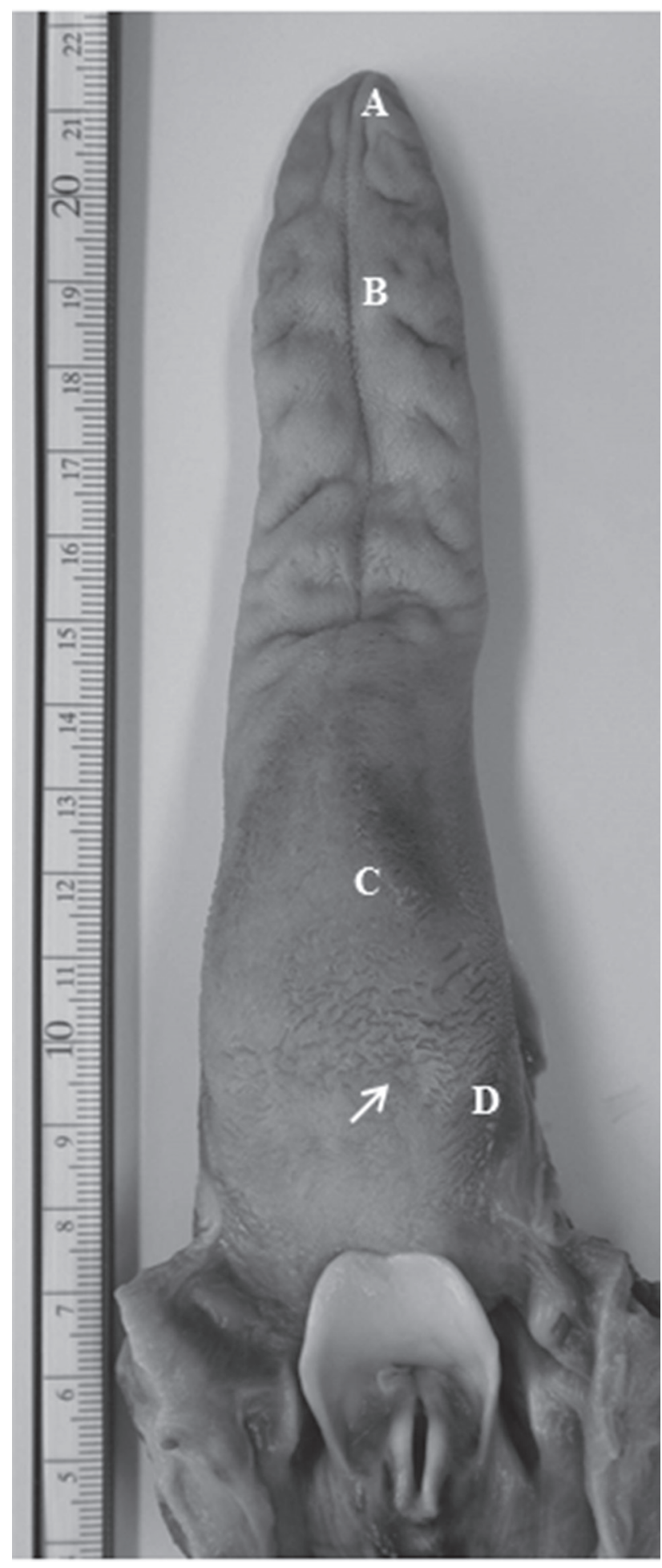

Fig. 1. Macrograph of an eastern grey kangaroo. $\mathrm{A}=$ lingual apex. $\mathrm{B}=$ lingual body. $\mathrm{C}=$ prominence of the lingual body. $\mathrm{D}=$ posterolateral margin of the lingual body. Arrow = vallate papilla.

2b). The filiform papillae on the lingual posterior body were thread-like in shape (Fig. 4a). The connective tissue core of the filiform papillae on the lingual posterior body consisted of many slender processes (Fig. 4b). The fungiform papillae were round in shape (Fig. 2a, 3). Three vallate papillae with the apex of the triangle directed posteriorly consisted of a groove and pad (Fig. 5a). Several conical papillae derived from the posterolateral margin of the tongue where foliate papillae have been shown to be distributed in many other animal species. Opening of the glandular duct on the posterolateral region were found (Fig. 5b).

\section{Discussion}

Krause and Cutts (1982) reported that the compound filiform papilla is a characteristic of most marsupials and the vallate papillae have a typical appearance of round bodies surrounded by deep furrows. The foliate papillae were not observed. Furthermore, in the genus Didelphis, elongated mucosal folds with numerous, irregular, fingerlike projections were identified on the posterolateral borders where foliate papillae are normally found in other species. Kobayashi et al. (2003) reported that the external form and connective tissue core of the filiform papillae of koalas consist of one large main process and several smaller accessory ones. Three vallate papillae were identified: one central midline (round type) and two laterally located (slit-like type) ones. Long conical papillae were shown to be distributed in the posterior lateral area where the foliate papillae are distributed in many other animal species. Emura et al. (2004) reported that on the posterior region of the red kangaroo, the filiform papillae of two types observed. Type 1 had a hair-like shape. Type 2 had a cylindrical shape and was thicker than the filiform papillae of type 1 . There were three vallate papillae on posterior region of the lingual body. No foliate papillae were clear on the posterolateral region. Openings of the glandular ducts on the posterolateral region were found. Emura (2011) reported that the sugar glider has a triangular arrangement of the three vallate papillae, with the apex of the triangle directed posteriorly. Undeveloped foliate papillae were observed on the posterolateral regions of the tongue. Emura et al. (2014) reported that the filiform and fungiform papillae on the lingual apex and body of the brush-tailed rat kangaroo consisted of a main papilla and secondary papillae. The connective tissue core of the filiform papillae on the lingual apex was cylindrical in shape with a crushed top. The connective tissue core of the filiform papillae on the lingual body had one large and several small processes. The surface of the vallate papillae was rough and the papillae were surrounded by a groove and a pad. Several long conical papillae derived from the posterolateral margin of the tongue where foliate papillae have been shown to be distributed in many other animal species. In this study, the filiform papillae on the lingual apex and body 

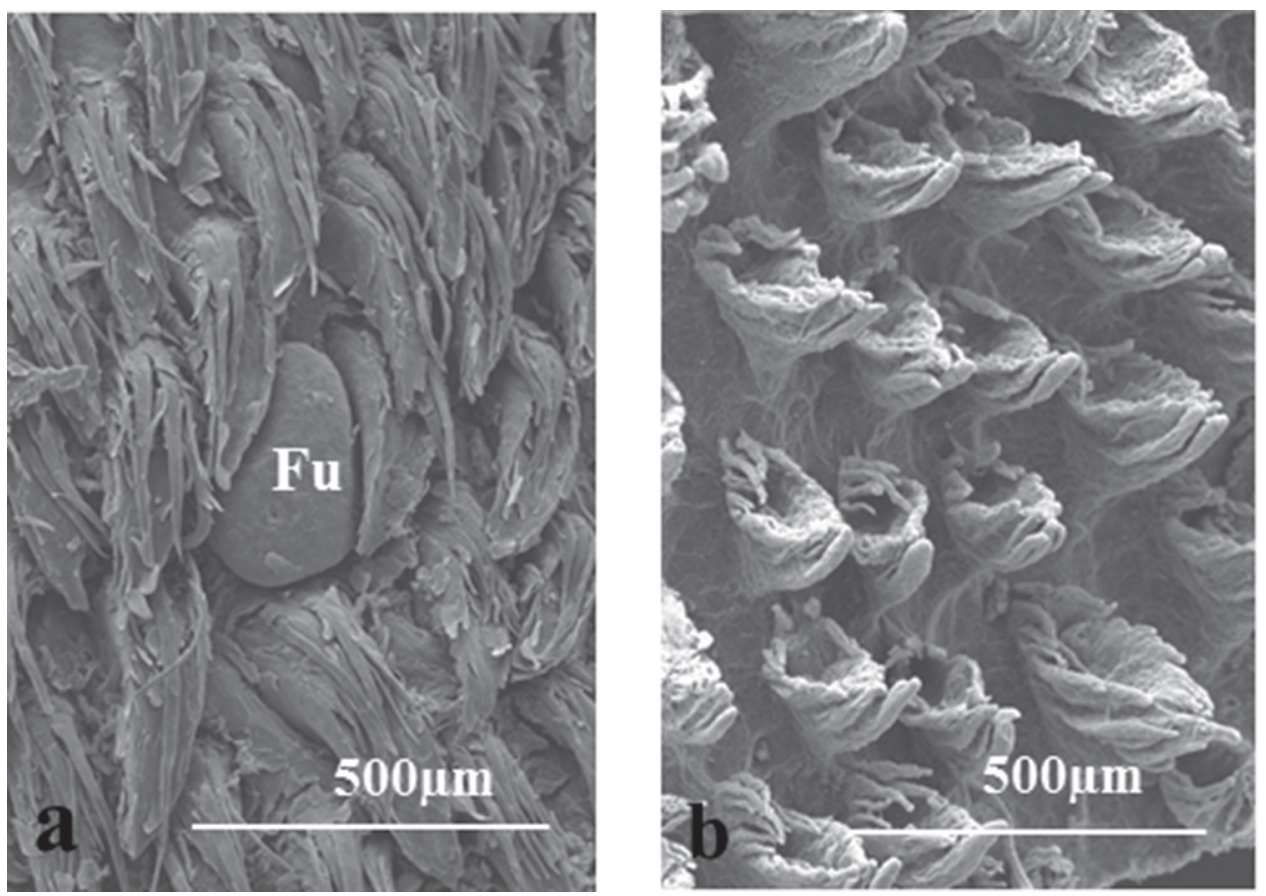

Fig. 2. Scanning electron micrographs of the eastern grey kangaroo tongue. (a) The filiform papillae on the lingual apex consist of a main papilla and secondary papillae. The fungiform papilla is round in shape. (b) The connective tissue core of the filiform papillae on the lingual apex has several processes.

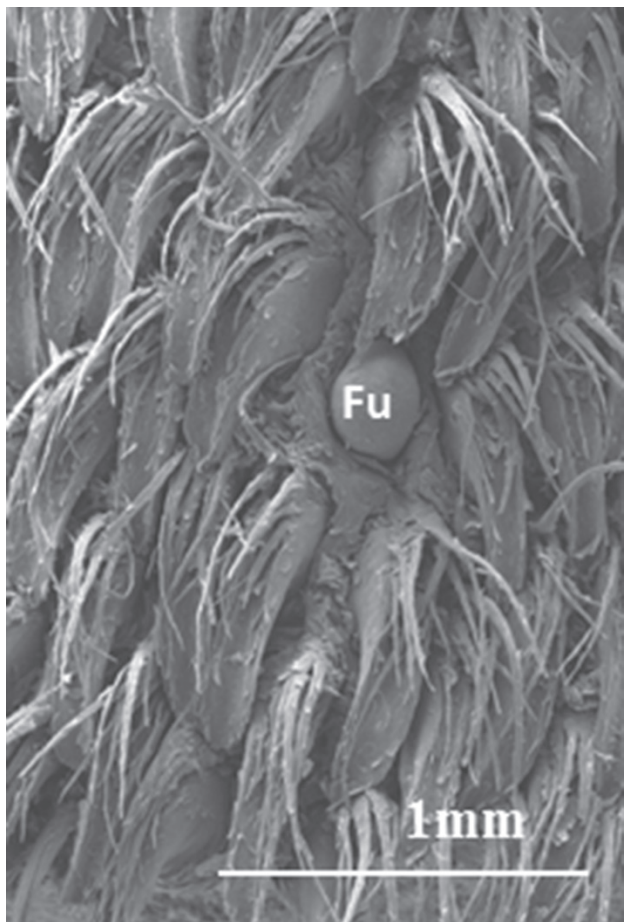

Fig. 3. Scanning electron micrographs of the eastern grey kangaroo tongue. The filiform papillae on the lingual apex consist of a main papilla and secondary papillae. consisted of one main papilla and secondary papillae. The surface of the three vallate papillae with the apex of the triangle directed posteriorly was rough and the papillae were surrounded by a groove and a pad. Several long conical papillae derived from the posterolateral margin of the tongue where foliate papillae have been shown to be distributed in many other animal species. Therefore, the lingual papillae of the eastern grey kangaroo are generally similar to those of the red kangaroo.

Three vallate papillae were also found on the tongues of marsupials (Kubota et al., 1963; Krause and Cutts, 1982; Kobayashi et al., 2003; Emura, 2011), primates (Kubota and Hayama, 1964; Emura et al., 2002a), rodents (Kubota and Togawa, 1966; Emura et al., 1999), lagomorphs (Kubota, 1966), insectivores (Chunhabundit et al., 1992) and Chiroptera (Emura et al., 2001; Emura et al., 2002b). In this study, the eastern grey kangaroo showed a triangular arrangement of the three vallate papillae, with the apex of the triangle directed posteriorly. Considering the number of vallate papillae on the tongue surface in this and previous studies, the number of vallate papillae may differ among species. However, further study is required to clarify the relationship between the species and the number of vallate papillae.

The foliate papillae were found generally to be developed in the orders Rodentia (Emura et al., 2011), Hyracoidea (Emura et al., 2008), Perissodactyla (Pfeiffer et al., 

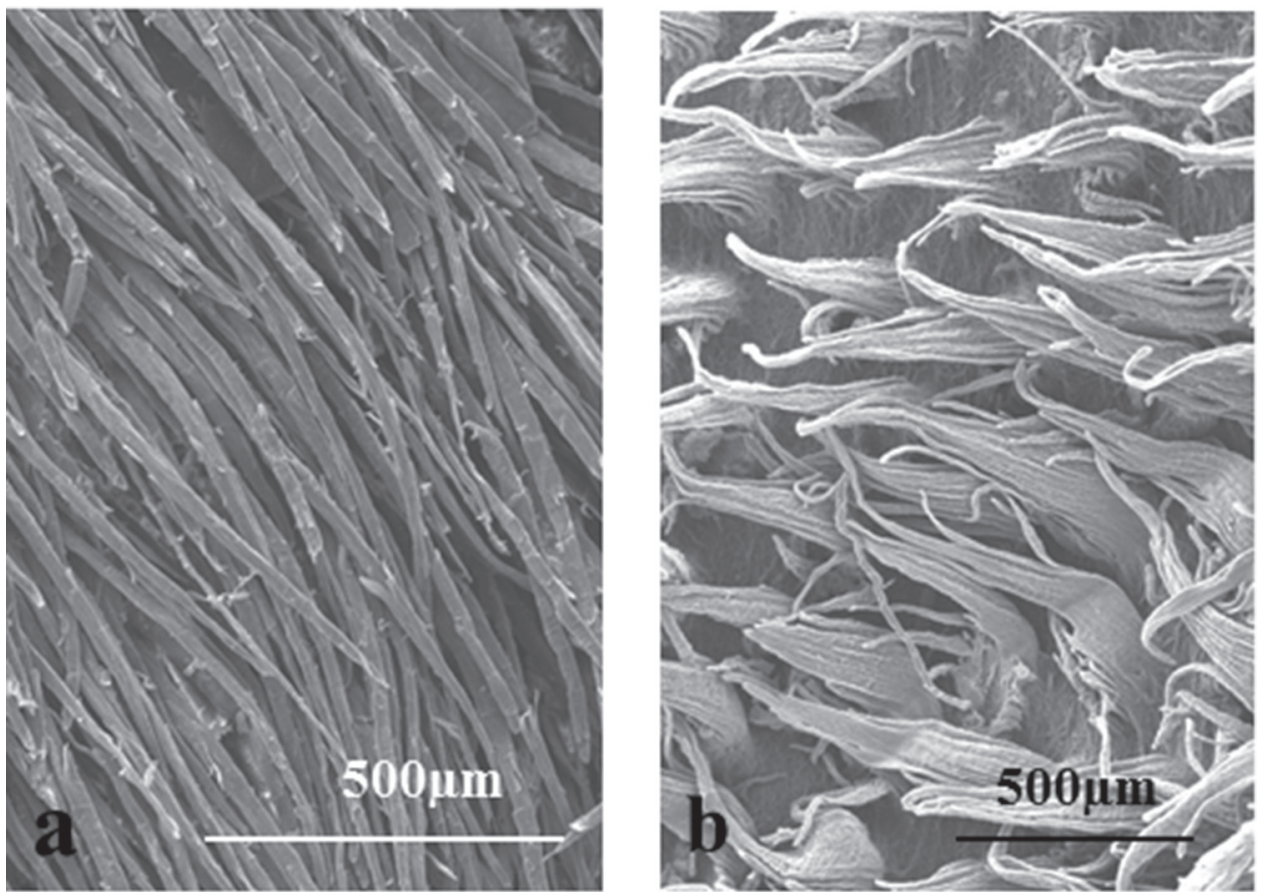

Fig. 4. Scanning electron micrographs of the eastern grey kangaroo tongue. (a) The surface prominence of the lingual body is hair-like in shape. (b) The connective tissue core of the filiform papillae on the lingual posterior body consists of many slender processes
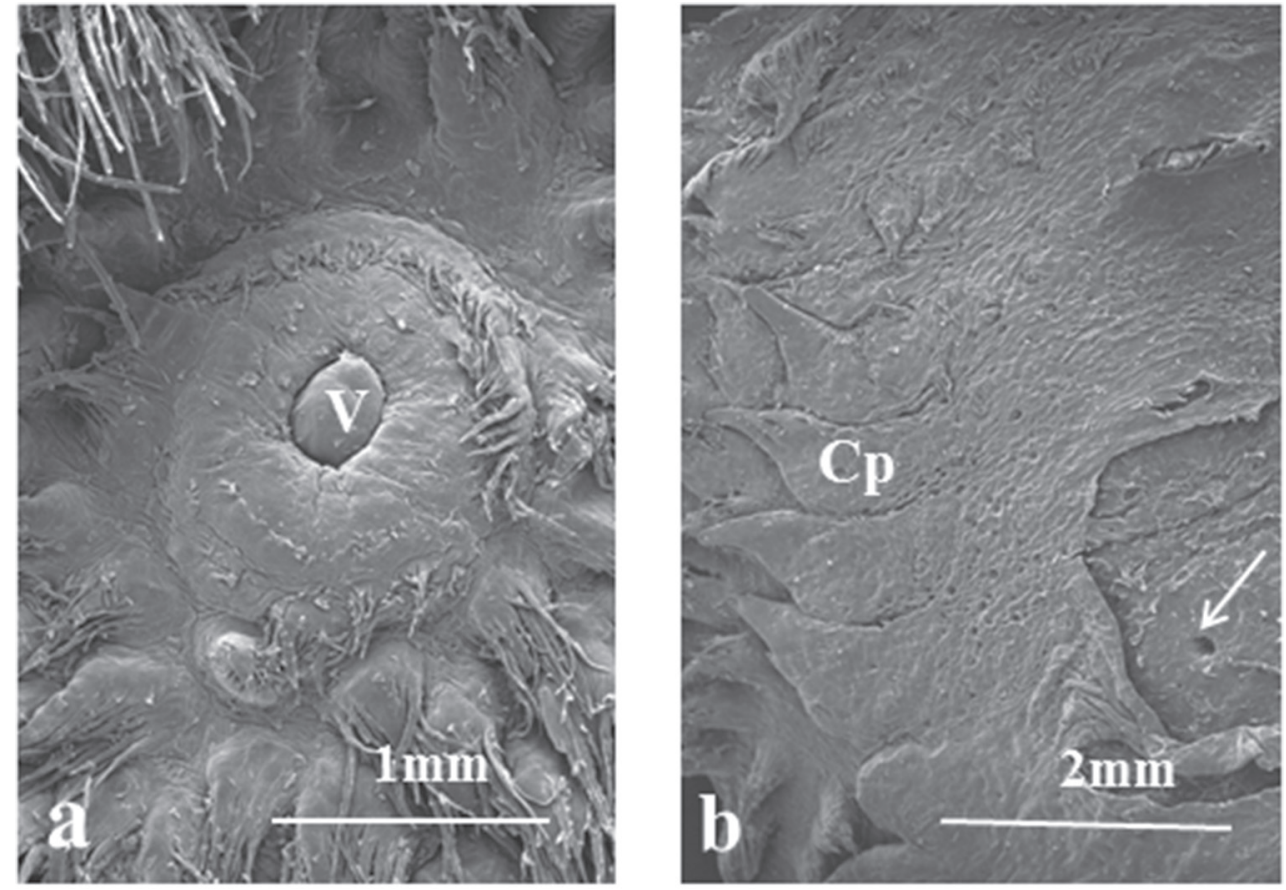

Fig. 5. Scanning electron micrographs of the eastern grey kangaroo tongue. (a) The vallate papilla consists of a groove and pad. (b) Several conical papillae derive from the posterolateral margin of the tongue where foliate papillae are distributed in many other animal species. $\mathrm{V}=\mathrm{val}-$ late papilla. $\mathrm{Cp}=$ conical papilla. Arrow $=$ opening of the lingual gland. 
2000) and primates (Emura et al., 2002a), but completely absent or rudimentary in the orders Artiodactyla (Emura et al., 2000), Carnivora (Emura et al., 2004) and Chiroptera (Emura et al., 2001, 2002b). In the order Marsupialia (Emura et al., 2014), several finger-like projections or long conical papillae derived from the posterolateral margin of the tongue where foliate papillae have been found to be distributed in many other animal species. My observations revealed similar foliate papillae in the eastern grey kangaroo, which exhibited morphological features typical for this type of papilla.

\section{Acknowledgements}

We are grateful to the staff of Tennoji Zoo, Osaka, Japan for supplying the specimen.

\section{References}

1) Chunhabundit $P$, Thongpila $S$ and Somana R. SEM study on the dorsal lingual surface of the common tree shrew, Tupaia glis. Acta Anat 1992; 143:253-257.

2) Emura S. SEM study on the tongue of the sugar glider (in Japanese). Med Biol 2011; 155: 377-383.

3) Emura S, Hayakawa D, Chen H and Shoumura S. Morphology of the dorsal lingual papillae in the Japanese macaque and savanna monkey. Anat Histol Embryol 2002a; 31:313-316.

4) Emura S, Hayakawa D, Chen $H$ and Shoumura S. SEM and gross study on the lingual surface of the red kangaroo, Macropus rufus (in Japanese). Acta Sch Med Univ Gifu 2004;52:30-35.

5) Emura S, Hayakawa D, Chen H, Shoumura S, Atoji Y and Agungpriyono S. SEM study on the dorsal lingual surface of the lesser dog-faced fruit bat, Cynopterus brachyotis. Okajimas Folia Anat
Jpn 2001; 78:123-128.

6) Emura S, Hayakawa D, Chen H, Shoumura S, Atoji Y and Wijayanto H. SEM study on the dorsal lingual surface of the large flying fox, Pteropus vampyrus. Okajimas Folia Anat Jpn 2002b; 79:113-120.

7) Emura S, Okumura T, Chen H. Morphology of the lingual papillae and their connective tissue cores in the cape hyrax. Okajimas Folia Anat Jpn 2008; 85:29-34.

8) Emura S, Okumura T, Chen H. Morphology of the lingual papillae in the Patagonian cavy. Okajimas Folia Anat Jpn 2011; 88:121125 .

9) Emura S, Okumura T, Chen H. Morphology of the lingual papillae in the jaguar. Okajimas Folia Anat Jpn 2013a; 89:93-97.

10) Emura S, Okumura T, Chen H. Morphology of the lingual papillae in the giraffe. Okajimas Folia Anat Jpn 2013b; 89:99-103.

11) Emura T, Tamada A, Hayakawa D, Chen H, Jamali M, Taguchi H and Shoumura S. SEM study on the dorsal lingual surface of the flying squirrel, Petaurista leucogenys. Ann Anat 1999; 181:495498.

12) Kubota K. Comparative anatomical and neurohistological observations on the tongue of Japanese pika (Ochotona hyperborea yezoensis, Kishida). Anat Rec 1966; 154:1-12.

13) Krause WJ and Cutts GH. Morphological observations on the papillae of the opossum tongue. Acta Anat 1982; 113:159-168.

14) Kubota $\mathrm{K}$ and Hayama S. Comparative anatomical and neurohistological observations on the tongues of pigmy and common marmosets. Anat Rec 1964; 150:473-486.

15) Kubota K, Kubota J, Fukuda N, Asakura S, Nakagawa S and Masui M. Comparative anatomical and neurohistological observations on the tongue of the marsupials. Anat Rec 1963; 147:337353.

16) Kobayashi K, Kumakura M, Yoshimura K, Nonaka K, Murayama $\mathrm{T}$ and Henneberg M. Comparative morphological study of the lingual papillae and their connective tissue core of the koala. Anat Embryol 2003; 206:247-254.

17) Kubota $\mathrm{K}$ and Togawa $\mathrm{S}$. Comparative anatomical and neurohistological observations on the tongue of Japanese dormouse (Glims japonicus). Anat Rec 1966; 154:545-552. 